\title{
A Study on the Measuring Method of Work Parameters to Evaluate the Skill of FCAW Welding Trainee
}

\author{
Woo Hyeon Ju*, Hyeong Chang Ryu*, Kyeong Seob Lim* and Sang-Myung Cho**, $\dagger$ \\ *Dept. of Mechanical Engineering, Pukyong Nat'1 Univ, Busan, 48513, Korea \\ **Dept. of Materials system Engineering, Pukyong Nat'l Univ, Busan, 48513, Korea \\ †Corresponding author : pnwcho@pknu.ac.kr \\ (Received December 27, 2019 ; Revised February 12, 2020 ; Accepted March 25, 2020)
}

\begin{abstract}
On industrial sites, FCAW is mostly performed by welders. In general, welder functional level evaluation is performed based on the appearance and mechanical testing of beads after welding. However, the actual welding quality obtained in the field is determined by the fluctuating characteristics of the working variables, depending on the welder's skill. Therefore, with trainees, a rating system is needed to evaluate proficiency by measuring work parameters. In this study, two welding cameras were used to measure the work parameters of a welder who performed FCAW semi-automatic welding using $\mathrm{CO}_{2}$ gas. A method of grading the welder's proficiency by analyzing the average and standard deviation of work parameters, taking into account the important factors that affect weld quality, is presented. For Trainee to develop a desire to grow on their own, a method of grading proficiency was proposed using the changing characteristics of the work variables rather than the welding results.
\end{abstract}

Key Words : FCAW, Work parameter, Welder, Semi-automatic welding, Welder's skill, Welder training

\section{Introduction}

FCAW is mostly conducted by semi-automatic welding. In Korea, FCAW welders are most active in workshops such as shipyards. The welder's skill is typically evaluated by recording the results of defects, appearance of beads, etc. after welding, it can also be evaluated through mechanical tests. However, the welding quality obtained in the field is determined by the variation characteristics of the work parameters according to the welder's skill. Therefore, a simple and economic evaluation system is necessary to evaluate the skill of welding trainees by measuring the work parameters ${ }^{1-3)}$. Moreover, when grading the skill of trainees, it must be evaluated by more rationally measuring the operations of actual welders. By scoring the work parameters' variation characteristics and providing feedback to the trainees, they can develop greater interest and focus on honing their skills. Accordingly, this study seeks to establish a method for measuring the work parameters of FCAW welders, quantify the variation characteristics of the work parameters, and propose a method for grading their welding skill.

\section{Experimental method}

\subsection{Measured Four Work Parameters}

The four main work parameters measured in this study are torch height, welding speed, work angle, and travel angle ${ }^{4-6)}$. Torch height refers to the contact tip-to-workpiece distance (CTWD). Variations in these work parameters depend on the welder's skill and act as a factor that directly impacts welding quality. These variations in work parameters, the welder's empirical skill, were quantified and applied to the welder's skill evaluation and quality control.

\subsection{Specimen and experimental method}

The base metal used in this study was a $150 \mathrm{X} 100 \mathrm{X}$ $6 \mathrm{~mm}$ SM400. Four welders performed BOP welding in the flat position on the FCAW used in welder training. Welders $\mathrm{A}$ and $\mathrm{B}$ conducted straight welding, while 
Table 1 Welding condition of flat position FCAW

\begin{tabular}{|c|c|}
\hline Filler metal & AWS A5.20 E71T-1C $1.2 \mathrm{~mm}$ \\
\hline Base metal & SM400 $150 \times 100 \times 6 \mathrm{~mm}$ \\
\hline Current & $170 \sim 230 \mathrm{~A}$ \\
\hline Voltage & $21.6 \sim 25.4 \mathrm{~V}$ \\
\hline
\end{tabular}

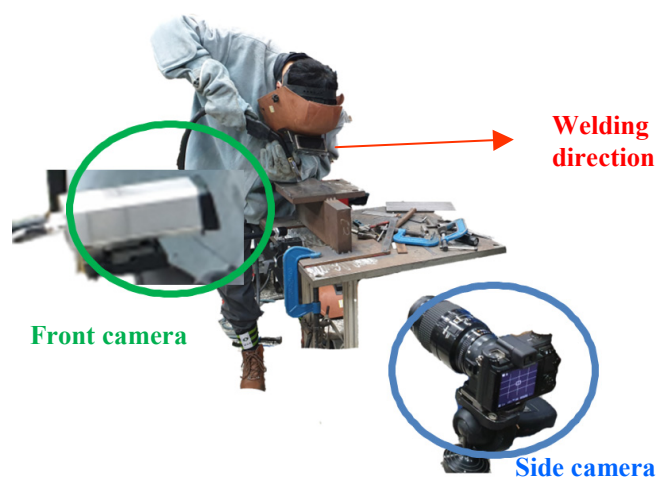

Fig. 1 Arrangement of welding cameras

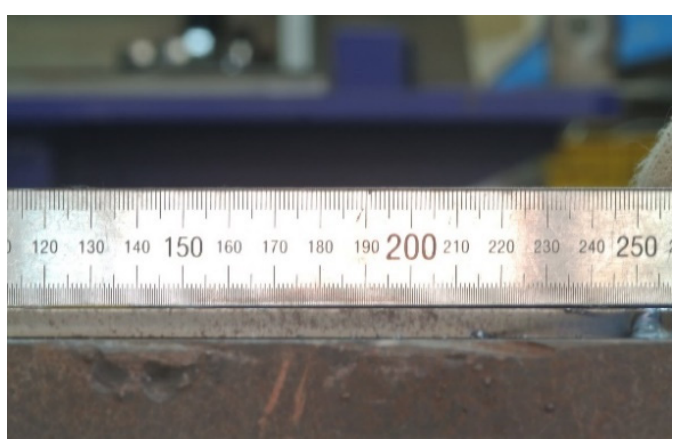

Fig. 2 Scale bar on welding plate

welders $\mathrm{C}$ and D conducted weaving welding. Table 1 shows the welding conditions used in the experiment.

\subsection{Work parameter photography and measurement}

Fig. 1 shows the arrangement of the welding cameras used in this experiment. A camera was arranged to photograph the side of the welding process and captured the welding speed, torch height, and travel angle $\left(\theta_{\mathrm{T}}\right)$. Another camera was arranged to photograph the front of the welding process and captured the work angle $\left(\theta_{\mathrm{W}}\right)$ and torch height.

Accounting for the distance between the camera and measurement target, just before welding, the side camera photographed a scale bar on a welding plate. Fig. 2 shows the photographed scale bar. To measure the torch height, travel angle $\left(\theta_{\mathrm{T}}\right)$, and welding speed, still images were acquired at 1-second intervals from the arc starting point of images captured by the side camera.

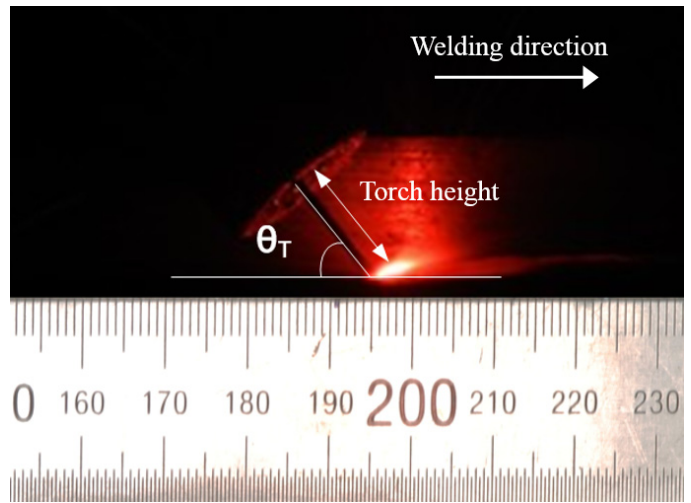

Fig. 3 Measurement by side camera video

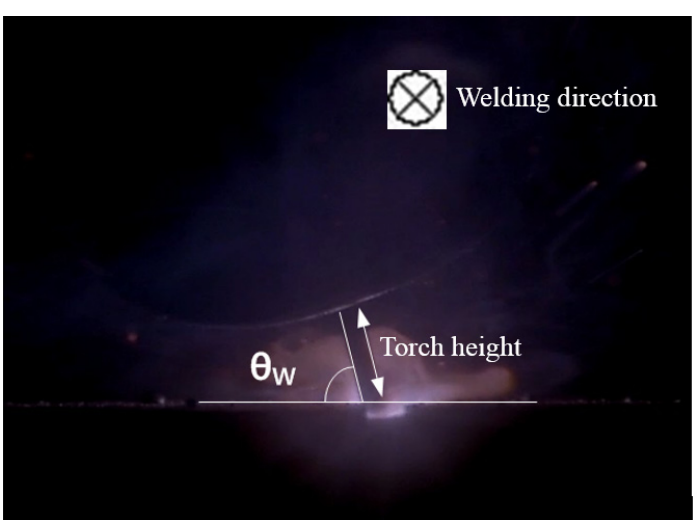

Fig. 4 Measurement by front camera video

Accordingly, the still images and scale bar were used to measure the torch height, travel angle $\left(\theta_{\mathrm{T}}\right)$, and welding speed at 1-second intervals. Fig. 3 shows the measurement of travel angle $\left(\theta_{\mathrm{T}}\right)$, welding speed, and torch height by the side camera. Fig. 4 shows the measurement of work angle $\left(\theta_{\mathrm{W}}\right)$ by the front camera. To correct the torch height error, it was calculated considering the work angle $\left(\theta_{\mathrm{W}}\right)$.

\section{Experimental results and discussion}

\subsection{Measurements of work parameters}

Fig. 5 shows the torch height variations when welders A and B performed straight welding. Fig. 6 shows the torch height variations when welders $\mathrm{C}$ and $\mathrm{D}$ performed weaving welding.

Fig. 7 shows the welding speed variations when welders $\mathrm{A}$ and $\mathrm{B}$ performed straight welding. Fig. 8 shows the welding speed variations when welders $C$ and D performed weaving welding.

Fig. 9 shows the work angle variations when welders A and B performed straight welding. Fig. 10 shows the work angle variations when welders $\mathrm{C}$ and $\mathrm{D}$ performed weaving welding. 


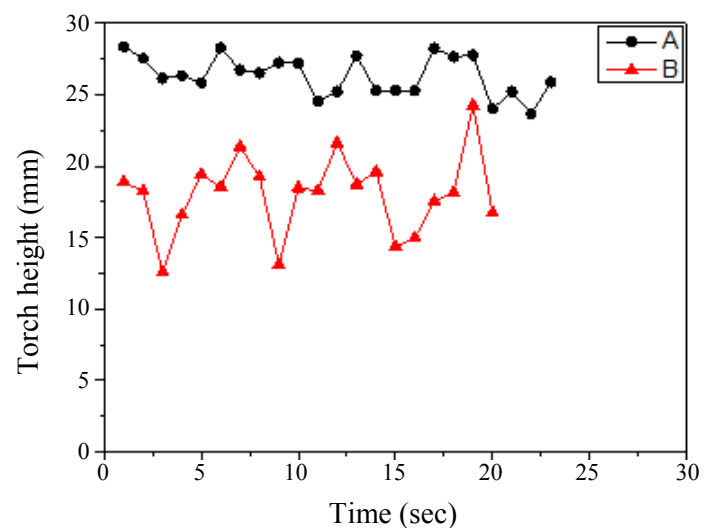

Fig. 5 Torch height variation graph of welder A and B

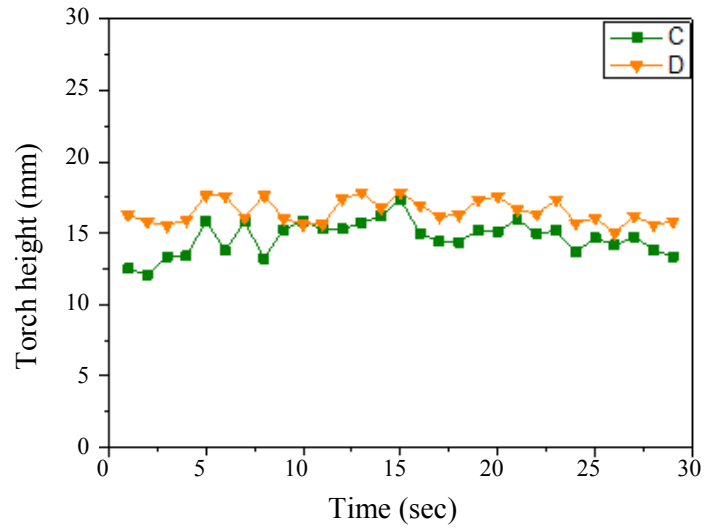

Fig. 6 Torch height variation graph of welder C and D

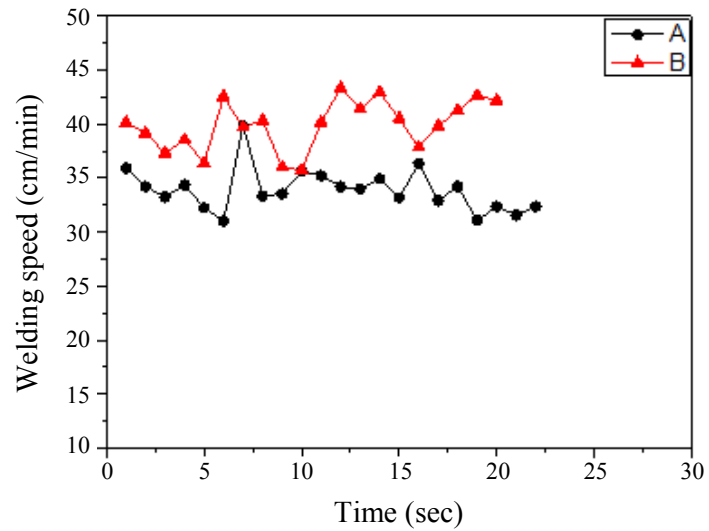

Fig. 7 Welding speed variation graph of welder A and B

Fig. 11 shows the travel angle variations when welders A and B performed straight welding. Fig. 12 shows the travel angle variations when welders $C$ and D performed weaving welding.

Table 2 presents the mean and standard deviation of the work parameters of welders A to D. To assess whether they were within the normal range of work parameters, the mean values of the work parameters were calculated. Moreover, since variations in the welder's

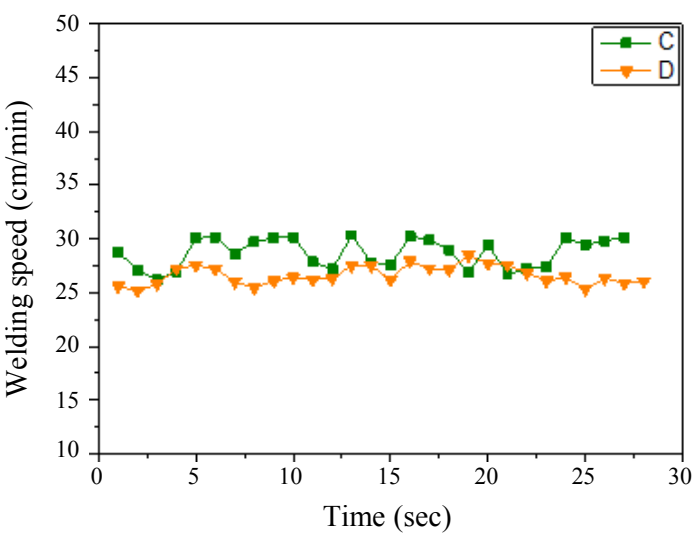

Fig. 8 Welding speed variation graph of welder C and D

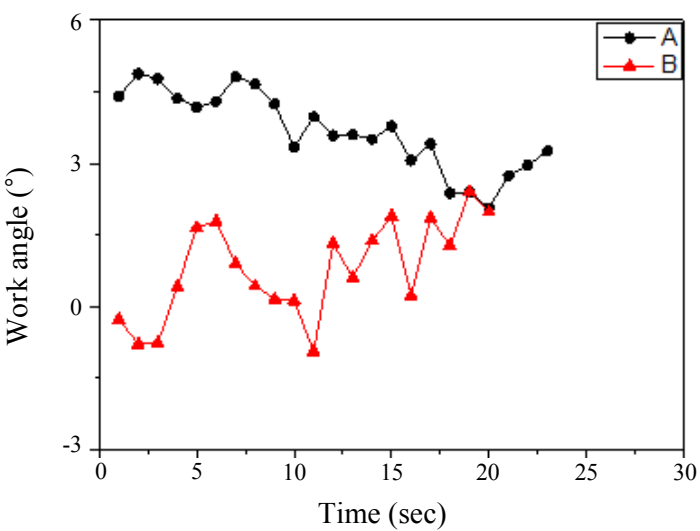

Fig. 9 Work angle variation graph of welder A and B

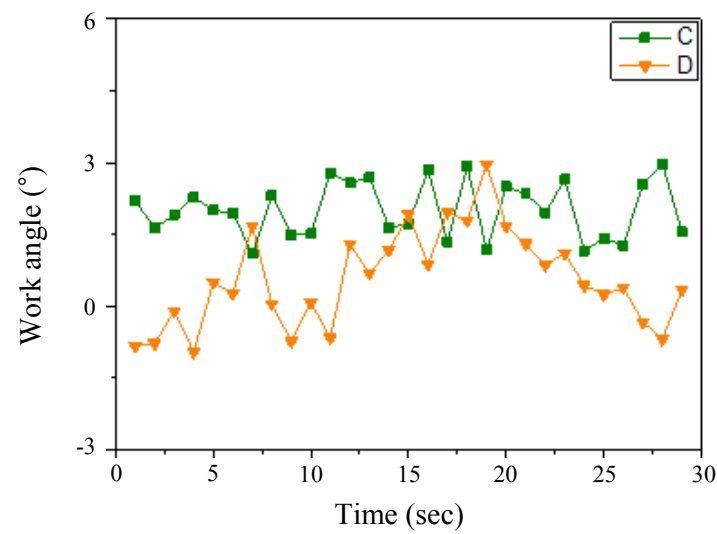

Fig. 10 Work angle variation graph of welder C and D

work parameters impact the welding quality, the standard deviation was calculated to evaluate the variation in work parameters ${ }^{4)}$.

\subsection{Evaluation method of work parameters}

To evaluate the skill of welders A-D, scores were assigned considering the mean and standard deviation of the work parameters. Weights were assigned as follows 


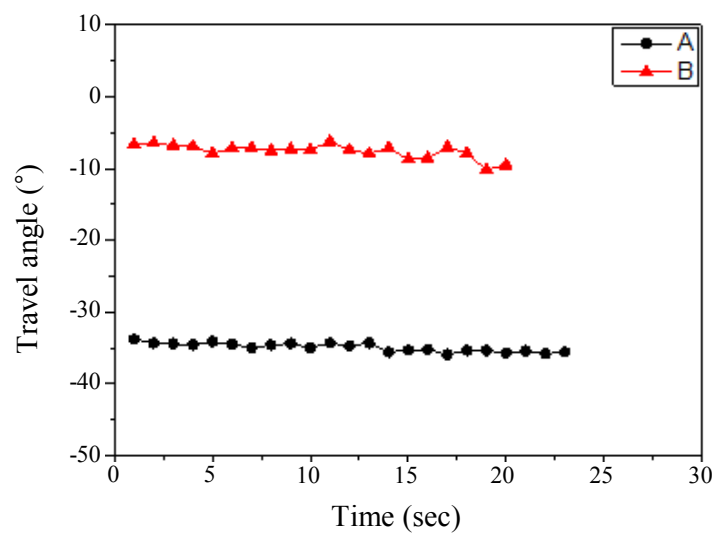

Fig. 11 Travel angle variation graph of welder A and B

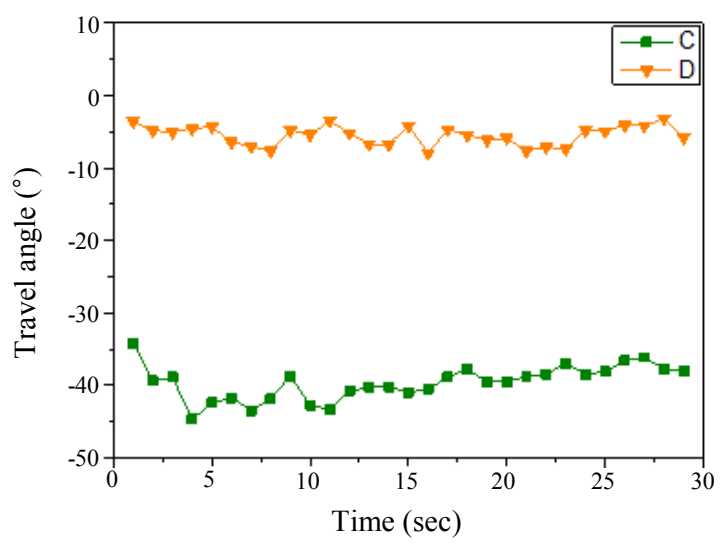

Fig. 12 Travel angle variation graph of welder C and D

Table 2 Average and standard of working parameter of welder A D

\begin{tabular}{|c|c|c|c|c|c|}
\hline Welder & $\begin{array}{l}\text { Statistical } \\
\text { method }\end{array}$ & $\begin{array}{l}\text { Torch } \\
\text { height }\end{array}$ & $\begin{array}{c}\text { Welding } \\
\text { speed }\end{array}$ & $\begin{array}{l}\text { Work } \\
\text { angle }\end{array}$ & $\begin{array}{c}\text { Travel } \\
\text { angle }\end{array}$ \\
\hline \multirow{2}{*}{ A } & Average & 26.35 & 33.9 & 3.68 & 34.92 \\
\hline & $\begin{array}{l}\text { Standard } \\
\text { Dev. }\end{array}$ & 1.36 & 1.95 & 0.81 & 0.59 \\
\hline \multirow{2}{*}{ B } & Average & 18.03 & 39.9 & 0.78 & 7.59 \\
\hline & $\begin{array}{c}\text { Standard } \\
\text { Dev. }\end{array}$ & 2.75 & 2.28 & 0.99 & 0.98 \\
\hline \multirow{2}{*}{$\mathrm{C}$} & Average & 26.35 & 33.9 & 3.68 & 34.92 \\
\hline & $\begin{array}{c}\text { Standard } \\
\text { Dev. }\end{array}$ & 1.36 & 1.95 & 0.81 & 0.59 \\
\hline \multirow[b]{2}{*}{ D } & Average & 18.03 & 39.9 & 0.78 & 7.59 \\
\hline & $\begin{array}{l}\text { Standard } \\
\text { Dev. }\end{array}$ & 2.75 & 2.28 & 0.99 & 0.98 \\
\hline
\end{tabular}

considering the importance of the work parameters impacting welding quality. The weight of torch height was assigned 3, welding speed 2, work angle 1, and travel speed 1. For torch height, the score was deducted when the mean deviated from the standard of $15 \mathrm{~mm}$. For welding speed, the score was deducted as the mean decreased, and for weaving welding, a lower level range
Table 3 Score table based on average and standard deviation of working parameters

\begin{tabular}{|c|c|c|c|c|c|c|}
\hline & \multirow{2}{*}{ Torch height } & \multicolumn{2}{|c|}{ Welding speed } & \multirow{2}{*}{$\begin{array}{l}\text { Work } \\
\text { angle }\end{array}$} & \multirow{2}{*}{$\begin{array}{l}\text { Travel } \\
\text { angle }\end{array}$} & \multirow{2}{*}{ Score } \\
\hline & & Straight & Weaving & & & \\
\hline \multirow{5}{*}{ Average } & Within $15 \pm 2$ & Over 50 & Over 30 & $0 \pm 2^{\circ}$ & $0 \pm 6^{\circ}$ & 5 \\
\hline & Within $15 \pm 4$ & Over 40 & Over 25 & $0 \pm 4^{\circ}$ & $0 \pm 12^{\circ}$ & 4 \\
\hline & Within $15 \pm 6$ & Over 30 & Over 20 & $0 \pm 6^{\circ}$ & $0 \pm 18^{\circ}$ & 3 \\
\hline & Within $15 \pm 8$ & Over 20 & Over 15 & $0 \pm 8^{\circ}$ & $0 \pm 24^{\circ}$ & 2 \\
\hline & Within $15 \pm 10$ & Over 10 & Over 10 & $0 \pm 10^{\circ}$ & $0 \pm 30^{\circ}$ & 1 \\
\hline \multirow{5}{*}{$\begin{array}{c}\text { Standard } \\
\text { Dev. }\end{array}$} & $0 \sim 1$ & \multicolumn{2}{|c|}{$0 \sim 1$} & $0 \sim 1$ & $0 \sim 1$ & 5 \\
\hline & $1 \sim 2$ & \multicolumn{2}{|c|}{$1 \sim 2$} & $1 \sim 2$ & $1 \sim 2$ & 4 \\
\hline & $2 \sim 3$ & \multicolumn{2}{|c|}{$2 \sim 3$} & $2 \sim 3$ & $2 \sim 3$ & 3 \\
\hline & $3 \sim 4$ & \multicolumn{2}{|c|}{$3 \sim 4$} & $3 \sim 4$ & $3 \sim 4$ & 2 \\
\hline & $4 \sim 5$ & \multicolumn{2}{|c|}{$4 \sim 5$} & $4 \sim 5$ & $4 \sim 5$ & 1 \\
\hline Weight & 3 & \multicolumn{2}{|c|}{2} & 1 & 1 & \\
\hline
\end{tabular}

Table 4 Classification table by total score

\begin{tabular}{|c|c|c|c|c|c|c|c|}
\hline & \multicolumn{7}{|c|}{ Total score } \\
\hline & $0 \sim 10$ & $11 \sim 20$ & $21 \sim 30$ & $31 \sim 40$ & $41 \sim 50$ & $51 \sim 60$ & $61 \sim 70$ \\
\hline Grade & 1 & 2 & 3 & 4 & 5 & 6 & 7 \\
\hline
\end{tabular}

than straight welding was applied. For work angle and travel angle, the score was deducted when the mean deviated from the standard of $0^{\circ}$. The greater the standard deviation of the work parameter, the more the score was deducted. The mean and standard deviation were reflected in the evaluation scores with equal weight. Table 3 shows the score distribution for the mean and standard deviation. Table 4 is a classification table according to the total evaluation scores.

\subsection{Work parameter evaluation results of welders $A-D$}

Table 5 shows the evaluation scores for the work parameters of welders A-D. Welder 7 showed the highest score at 67 , and was thus assigned Grade 7. Welders B and $\mathrm{C}$ scored 52 and 55 points, respectively and both were assigned Grade 6 . Welder A was assigned Grade 4 with 40 points. The welders who participated in this evaluation were highly skilled in the field and thus obtained high grades. However, when beginner trainees receive a low grade, their individual welding operations

Table 5 Score and grade of welder A D

\begin{tabular}{|c|c|c|c|c|}
\hline Welder & $\begin{array}{c}\text { Average } \\
\text { score }\end{array}$ & $\begin{array}{c}\text { Standard Dev. } \\
\text { Score }\end{array}$ & $\begin{array}{c}\text { Total } \\
\text { score }\end{array}$ & Grade \\
\hline A & 10 & 30 & 40 & 4 \\
\hline B & 27 & 25 & 52 & 6 \\
\hline C & 27 & 28 & 55 & 6 \\
\hline D & 33 & 34 & 67 & 7 \\
\hline
\end{tabular}




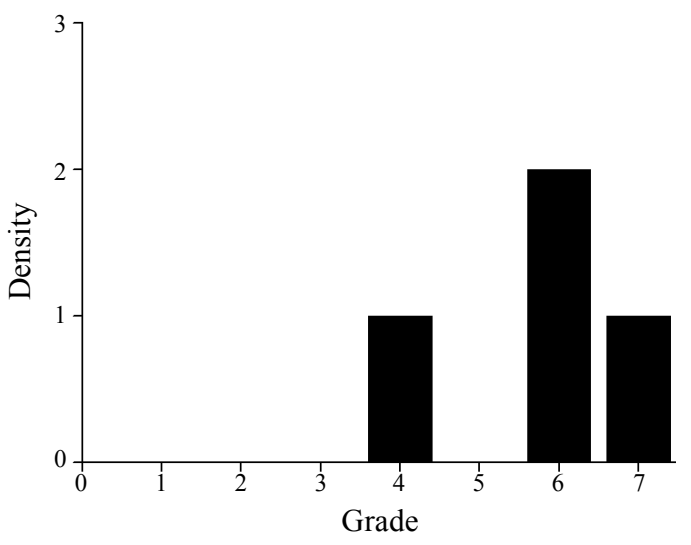

Fig. 13 Distribution of welder's grade in the form of probability density function

are quantitatively analyzed and the welder's skill is evaluated, thereby serving as individual feedback. Therefore, this system enables high-efficiency training and the trainee's psychology growth, inducing them to easily concentrate.

Fig. 13 is a graph of the four welders' grades expressed in the form of probability density functions. As the welders were all highly skilled, they are distributed among the higher grades. Meanwhile, beginners will be distributed among the lower grades, and the distribution characteristics will differ widely according to the learning group. Since these distribution characteristics can be used to easily evaluate the level of a group or corporate organization, they can also be easily applied to welding contracts.

\section{Conclusions}

To evaluate the functional levels of FCAW welders using work processes rather than welding results, the variation characteristics of four main work parameters (welding speed, torch height, work angle, and travel angle) were recorded in videos, measured, and analyzed, and the following conclusions were drawn.

1) This study proposed a method of measuring four main work parameters at 1-second intervals by taking videos of welders directly using an arc front camera, side camera, and scale.

2) When the welders' skill were evaluated considering the welding parameter's importance in quality: the weight of torch height was assigned 3, welding speed 2, work angle 1 , and travel angle 1 .
3) A system was presented in which the mean and standard deviation of the four work parameters are evaluated, scored with equal weight, and then provided to the trainees as feedback, though which they can hone their own skills.

4) A method was proposed for statistically evaluating the skill of a group or corporate organization by grading the welders' skill from 1 to 7 , based on evaluation of the variation characteristics of the work parameters.

\section{Acknowledgments}

This study was supported by the KEIT research fund of the Ministry of Trade, Industry and Energy. [No: 20003633]

ORCID: Woo Hyeon Ju: https://orcid.org/0000-0002-3140-8004 ORCID: Hyeong Chang Ryu: https://orcid.org/0000-0001-5382-6795 ORCID: Kyeong Seob Lim: https://orcid.org/0000-0001-6733-0643 ORCID: Sang-Myung Cho: https://orcid.org/0000-0001-6258-3625

\section{Reference}

1. C. S. Wu, Microcomputer-based welder training simulator, Comput Ind. 20(3) (1992) 321-325. https://doi.org/10.1016/016613615(92)90080-7

2. K. Fast, T. Gifford, R. Yancey, Virtual training for welding, Third IEEE and ACM International Symposium on Mixed and Augmented Reality (ISMAR 2004), Arlington, USA (2004).

3. S. H. Hwang, A study on Korean welding education and qualification system(I), J. Korean Weld. Join. Soc. 20(2) (2002) 4-12.

4. R. Stone, K. Watts, P. Zhong, C. S. Wei, Physical and cognitive effects of virtual reality integrated training, Hum Factors. 53(5) (2011) 558-572. https://doi.org/10.1177/0018720811413389

5. Steven W, Dirk R, Mores P, Christoph B, Terrence C, Virtual reality welder training, J. Ship Prod. Des. 22(3), (2006) 126-138. https://doi.org/10.1117/12.840473

6. E. Choi, J. Y. Kim, S. H. Shin, S. Y. Kim, A study on the analysis effectiveness of the virtual welding simulator for welding manpower development, J. Weld. Join. 33(3) (2015) 40-46. https://doi.org/10.5781/jwj.2015.33.3.40 